Delft University of Technology

\title{
Two-Port Dual-Band Microstrip Square-Ring Antenna for Radar Applications
}

Puskely, Jan; Yarovoy, A.G.; Roederer, Antoine

DOI

10.1109/EuCAP.2016.7481539

Publication date

2016

Published in

10th European Conference on Antennas and Propagation, EuCAP 2016

\section{Citation (APA)}

Puskely, J., Yarovoy, A. G., \& Roederer, A. (2016). Two-Port Dual-Band Microstrip Square-Ring Antenna for Radar Applications. In M. Mattes (Ed.), 10th European Conference on Antennas and Propagation, EuCAP 2016 (pp. 1-5). IEEE . https://doi.org/10.1109/EuCAP.2016.7481539

\section{Important note}

To cite this publication, please use the final published version (if applicable).

Please check the document version above.

\section{Copyright}

Other than for strictly personal use, it is not permitted to download, forward or distribute the text or part of it, without the consent of the author(s) and/or copyright holder(s), unless the work is under an open content license such as Creative Commons.

Takedown policy

Please contact us and provide details if you believe this document breaches copyrights.

We will remove access to the work immediately and investigate your claim. 


\title{
Two-Port Dual-Band Microstrip Square-Ring Antenna for Radar Applications
}

\author{
Jan Puskely, A. G. Yarovoy, A. G. Roederer \\ MS3, Department of Electrical Engineering, Delft University of Technology, 2628CD Delft, Netherlands \\ J.Puskely-1@tudelft.nl, A.Yarovoy@tudelft.nl, roederer.antoine@gmail.com
}

\begin{abstract}
A novel two-port, dual-band square-ring microstrip antenna element for wide-angle scanning planar phased array is proposed. The two ports are used to operate the antenna array over the $L$ and $S$ radar bands. Microstrip squarering radiators are chosen due to their smaller dimensions compared to the conventional microstrip patch. To extend operational bandwidth, the square rings placed into a single layer are fed by small coupling patches. The antenna elements demonstrate consistent radiation patterns and sufficient bandwidths in both operational bands. Due to its dimensions, the element is well-suited for application to wide-scan phased arrays.
\end{abstract}

Index Terms-square-ring, dual-band, two-port, phased arrays, L-band, S-band, radar.

\section{INTRODUCTION}

Wide-angle scanning arrays have re-gained increasing attention in recent years for wideband radio astronomy, satellite communication, $5 \mathrm{G}$ wireless and radar applications [1]. Special attention received antenna arrays supporting different functional tasks using the same aperture in different frequency bands. The operational requirements for these arrays put high demands on the design of antenna element in terms of size, feeding technique, radiation pattern, coupling, etc. Many antenna elements have been proposed in the development of wideband [2-5] as well as dual- or multi-band designs in the literature [6-9] but mostly only with single port covering all bands. Using separate feeding ports for separate bands is however attractive option for some applications, including radar systems, and the aim of the work is to design two port dual-band antenna element enabling wide bandwidth and wideangle scanning performances of antenna arrays in both bands.

Microstrip patch antennas [5-6] belong to the most popular and widely used radiating elements for phased array systems, due to their relative ease of manufacturing, low cost, light weight and low profile. Slotted patches have often been proposed to meet dual-band operation requirements [7-9]. However, these elements have some limitations such as large electrical dimensions, asymmetric or inconsistent radiation patterns or extremely narrow bandwidths. Another problem is to achieve two port feeding for such elements.

In this paper, we propose a novel concept of two-port dualband antenna for wide-angle scanning planar phased array. Microstrip square-ring radiators are chosen as radiating

This research is conducted as part of the Sensor Technology Applied in Reconfigurable systems for sustainable Security (STARS) project. For further information: www.starsproject.nl. elements due to their smaller dimensions compared to the conventional microstrip patch. To extend operational bandwidth, the square rings placed into a single layer are fed by small coupling patches. The antenna element structure and stand-alone element performance are described in Section II. Performance of the element in infinite and finite arrays is presented in Sections III and IV correspondingly. The results summarized in Chapter V.

\section{TWO-PORT, DUAL BAND ANTENNA DESIGN}

There are two key functional aspects of the antenna design: the radiating elements and the feeding of this element. In wide angle scanning radar systems, the required dimensions for the element are so small that a simple patch antenna would require a relatively high permittivity substrate which would reduce its bandwidth. To decrease the dimensions of the antenna element without using high permittivity substrate, the microstrip square-ring is used instead of a conventional circular or rectangular microstrip patch. As a coaxial feeding pin seriously limits the bandwidth, EM coupled feed using a small parasitic patch is selected for this design. The advantage of this design is that there is space left inside the ring to place another smaller element to cover the high frequency band. In our case it is also a square microstrip ring.

So the antenna element consists of two concentric square microstrip rings, coupled to separate small patches, each connected to a separate port: one for L-band and the other for S-band. Both rings are placed on a substrate with a dielectric permittivity of 3.5 and a thickness of $1.6 \mathrm{~mm}$. The layer with rings is placed at height $t$ above the ground plane and surrounded with a square cavity. The feeding of the coupling patches is done by coaxial probes through the ground plane. The whole antenna structure is shown in Fig.1. The dimensions of the dual-band antenna are listed in Table I.

TABLE I. DIMENSIONS OF THE ANTENNA ELEMENT IN FIG. 1

\begin{tabular}{cc|cc}
\hline \hline Parameters & Value $[\mathrm{mm}]$ & Parameters & Value $[\mathrm{mm}]$ \\
\hline$t$ & 12 & $W_{3}$ & 2 \\
$U_{\text {cell }}$ & 65 & $L_{4}$ & 9 \\
$L_{1}$ & 50 & $W_{4}$ & 2 \\
$w_{1}$ & 7.5 & $s_{1}$ & 1 \\
$L_{2}$ & 23.8 & $s_{2}$ & 1 \\
$w_{2}$ & 3.15 & $d$ & 2 \\
$L_{3}$ & 3.4 & $p$ & 7.5
\end{tabular}




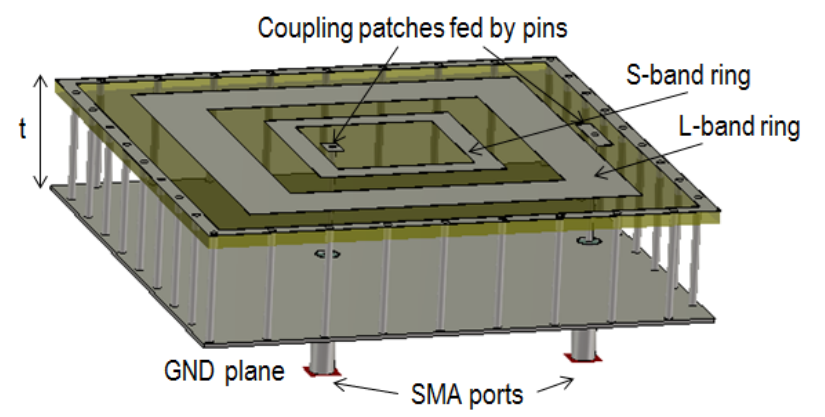

(a)

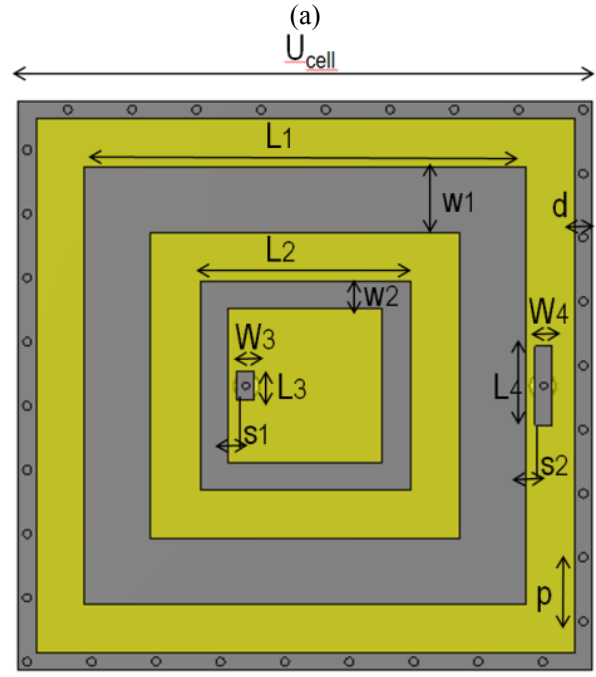

(b)

Fig. 1. (a) The geometry of dual-band dual-feed microstrip square-ring antenna; (b) Top view on the antenna element.

In order to demonstrate the characteristics of the proposed dual-band antenna, simulated input reflection coefficients and radiation patterns of the stand-alone antenna, for operation at L-band and S-band, are presented in Fig. 2 and Fig. 3. The antenna modelling was carried out with in CST-MWS ${ }^{\mathrm{TM}}$ and the impedance was matched to $50 \Omega$ for the simulations.

Figure 2 shows the simulated reflection coefficients of the proposed antenna. The operational bandwidth in L-band is 40 $\mathrm{MHz}$ at the center frequency of $1.4 \mathrm{GHz}$. The simulated bandwidth at S-band is about $500 \mathrm{MHz}(2.6-3.1 \mathrm{GHz})$. The isolation between both rings is less than $-20 \mathrm{~dB}$ in both bands. The bandwidth at L-band could be insufficient for some applications and can be increased by use of a two layer arrangement, the lower layer supporting the smaller ring. This is the goal of ongoing work.

The simulated patterns at the center frequencies of the low and high bands are presented in Fig. 3. The geometry has been optimized to produce nearly symmetrical radiation patterns in both bands. The feeding by coaxial probes is responsible for the small asymmetry of the radiation patterns in the H-plane, especially in the higher frequency band. The low levels of cross polarization, below $-25 \mathrm{~dB}$, are maintained in both bands over the entire angular range, excepted in the E-plane in the high frequency band (see Fig. 3b). In this case the cross polarization is less than $-10 \mathrm{~dB}$ in the desired angular range. This could affect the scanning performances at wide angles and further work is currently focused on the improvement of cross polarization characteristics in the S-band.

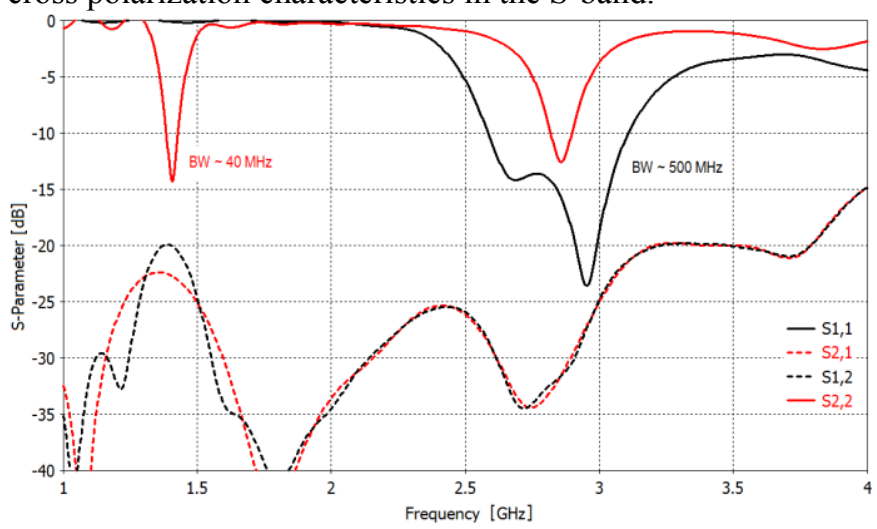

Fig. 2. Simulated reflection coefficients and coupling for L-band and Sband.

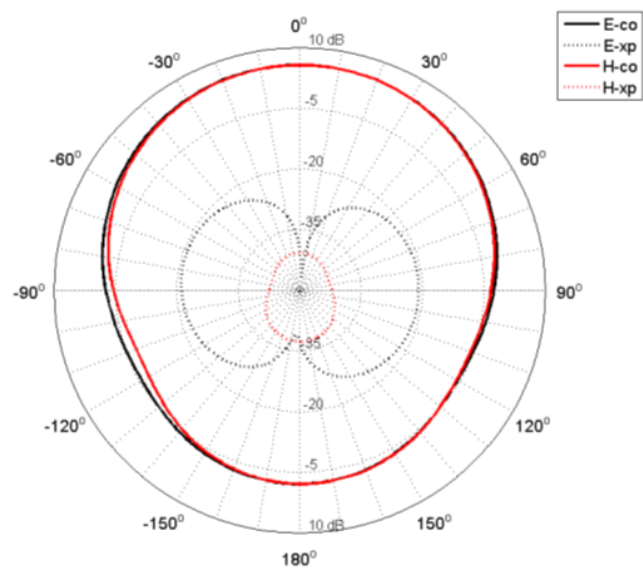

(a)

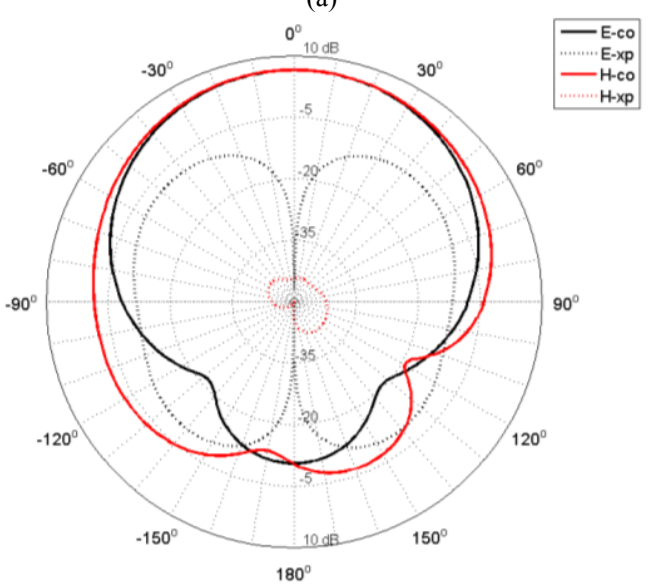

(b)

Fig. 3. Simulated radiation patterns at (a) L-band and (b) S-band.

The unit-cell of the antenna measures $0.29 \lambda_{\mathrm{L}} \times 0.29 \lambda_{\mathrm{L}}$, at the low frequency band. This provides the possibility to achieve scanning over more than $+/-60^{\circ}$. But in the higher frequency band the spacing is $0.65 \lambda_{\mathrm{s}}$. This provides a scan angle range of just over a little more than $+/-30^{\circ}$ respecting a grid spacing $\mathrm{d}_{\mathrm{e}}=\lambda_{\mathrm{op}} /\left(1+\sin \theta_{\max }\right)$. This limitation can be avoided by using a multi-scale array configuration [6]. 


\section{INFINITE ANTENNA ARRAY ANALYSIS}

To analyze the infinite antenna array we use a multi-scale array configuration. As illustrated in Fig. 4, each unit cell of this array will have one dual band element and three high frequency elements. In this array configuration, an equilateral triangular lattice is used for both bands. The distance between two S-band elements is $55 \mathrm{~mm}\left(0.55 \lambda_{\mathrm{S}}\right)$ and consequently $110 \mathrm{~mm}\left(0.55 \lambda_{\mathrm{L}}\right)$ between two L-band elements.

The simulated input reflection coefficients and radiation patterns of the stand-alone antenna elements P3, P4 and P5 for operation at S-band, are shown in Figs. 5-6. The bandwidth of both elements exceeds $300 \mathrm{MHz}(2.8-3.1 \mathrm{GHz})$.

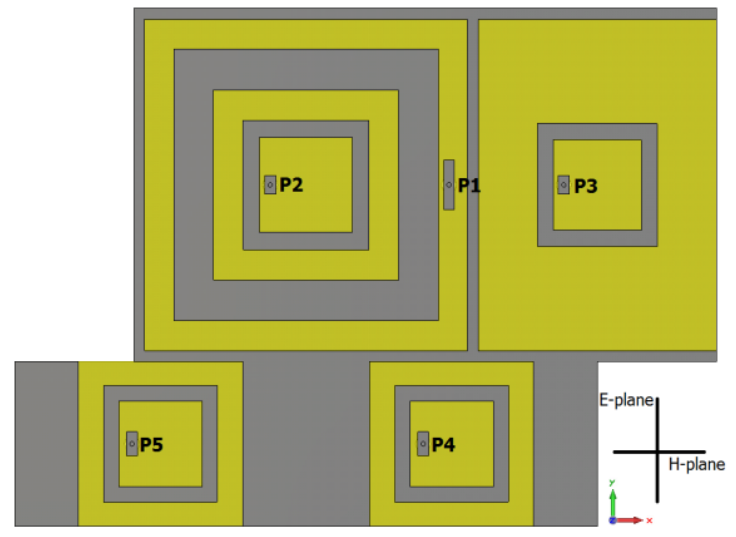

Fig. 4. The unit cell of a multi-scale array configuration.

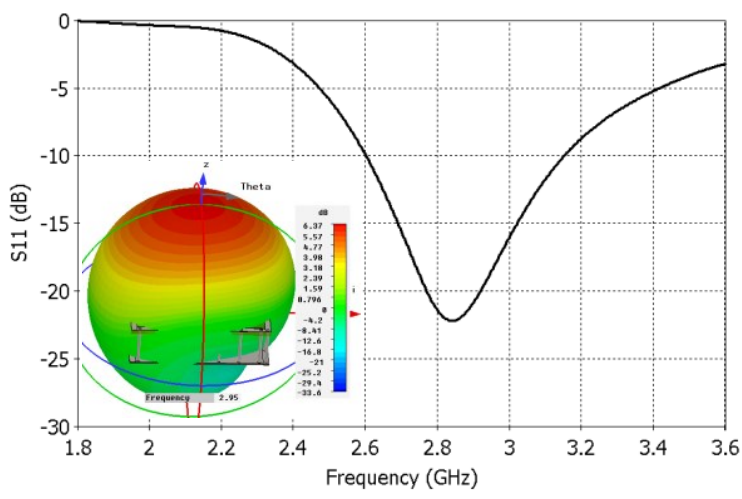

Fig. 5. Simulated reflection coefficients and radiation patterns at $2.95 \mathrm{GHz}$ of element P3.

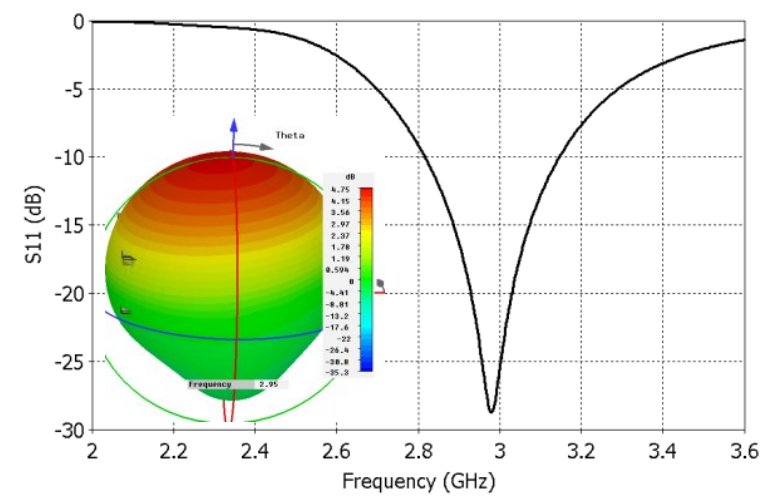

Fig. 6. Simulated reflection coefficients and radiation patterns at $2.95 \mathrm{GHz}$ of element P4 and P5.
The active reflection coefficients as a function of the scan angle for L-band operation are shown in Fig 7. The variation is more constrained in the H-plane due to lower mutual coupling. In the E-plane the deviations are larger.

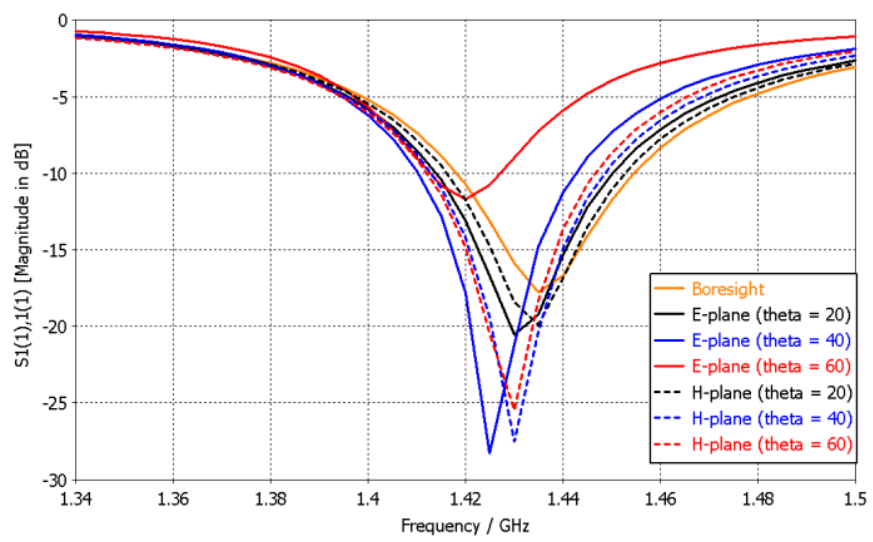

Fig. 7. Active reflection coefficients of the infinite array at L-band; port 1 .

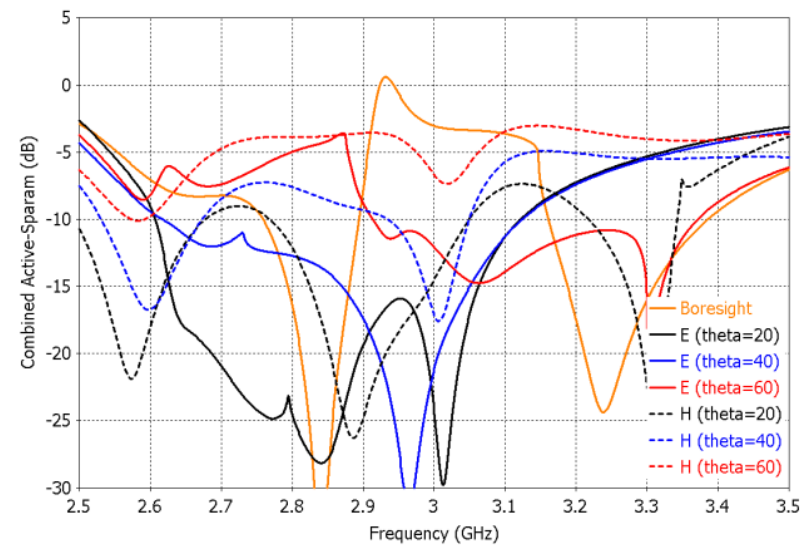

Fig. 8. Combined active reflection coefficients of the infinite array at Sband; P2.

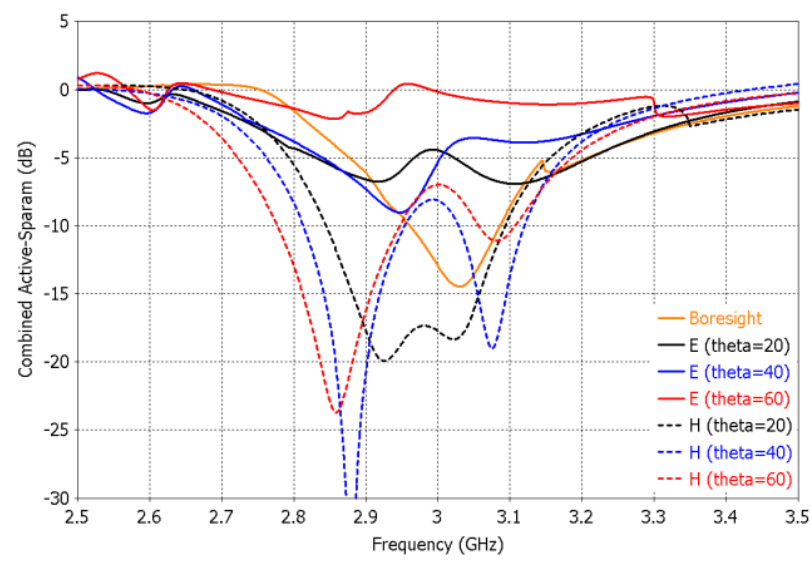

Fig. 9. Combined active reflection coefficients of the infinite array at Sband; P4.

The active reflection coefficients for the elements $\mathrm{P} 2$ and P4 in S-band are presented in Figs. 8-9. Due to the fact the unit cell in infinite antenna array configuration consists of five ports the active S-parameter of each port is calculated by combination of all ports respecting the phase shifts for given 
scan angle. Obviously, the obtained results don't correspond to our assumption, even for boresight. That's why we verify the results of active reflection coefficients in finite array configuration too.

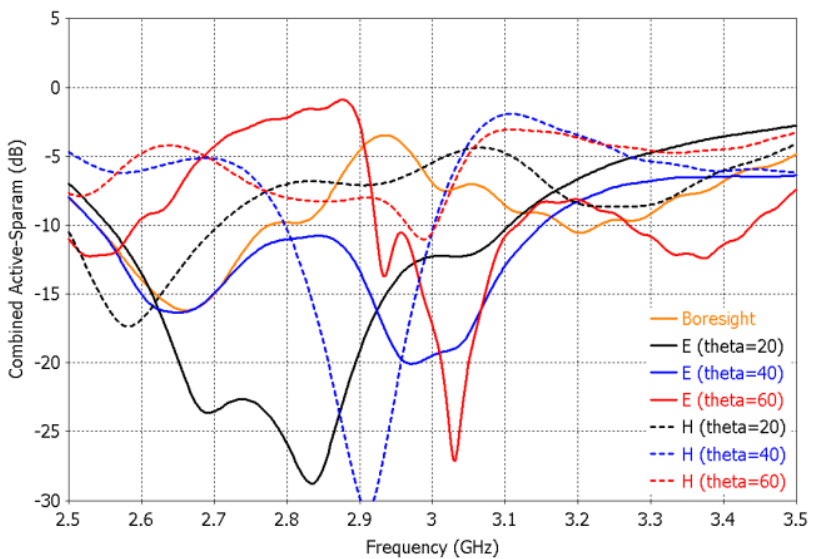

Fig. 10. Active reflection coefficient of central subarray of finite array from Fig. 12; P2.

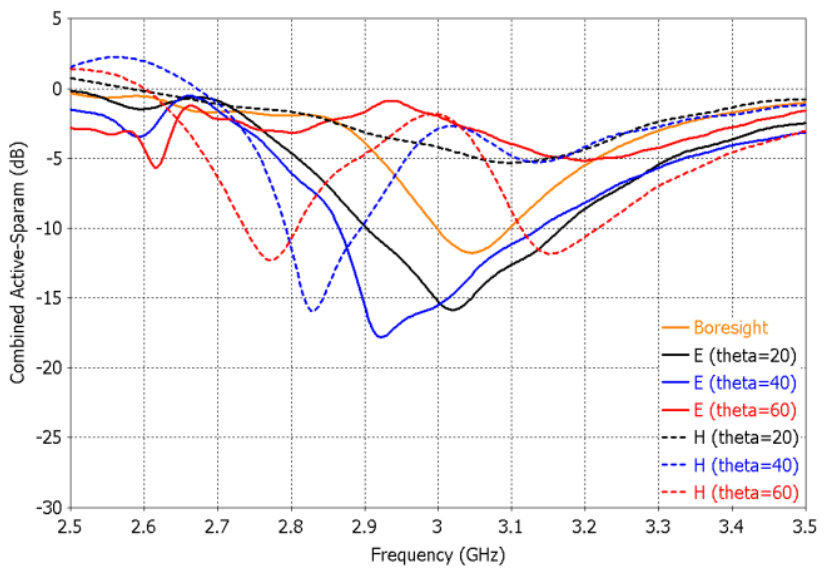

Fig. 11. Active reflection coefficient of central subarray of finite array from Fig. 12; P4.

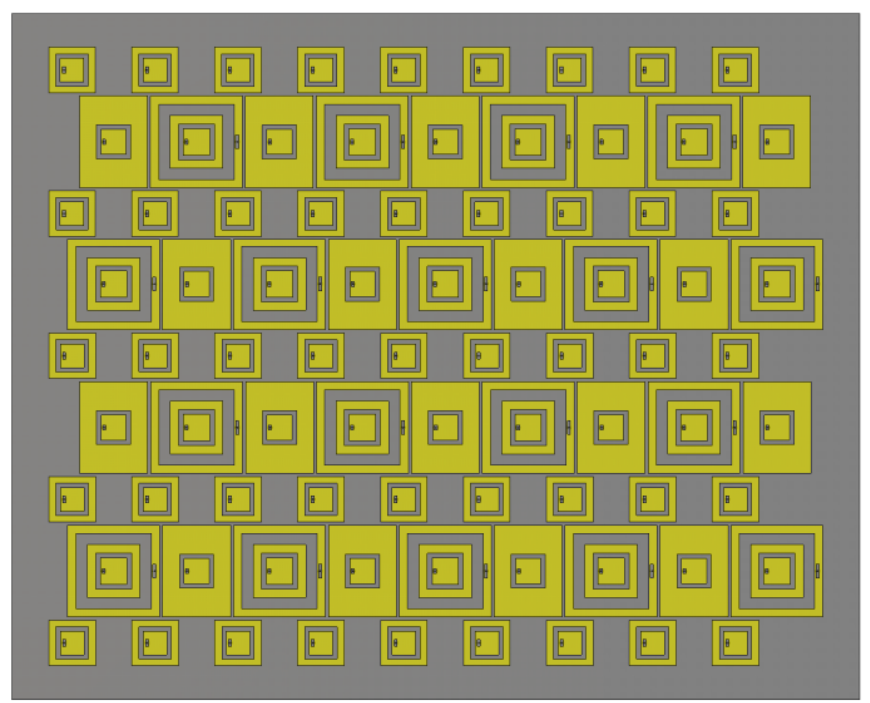

Fig. 12. The numerical model of 9x9 multi-scale array topology.

\section{FINITE ANTENNA ARRAY ANALYSIS}

In order to illustrate the scanning performance supported by the array antenna in both operational bands and to verify active reflection coefficients of infinite array from previous part, the numerical model of 9x9 element was designed (Fig. 12). For the lower operational band four (five) elements are used in each row while for the higher operational band the nine elements are used. The uniform amplitude distribution is considered for the beam scanning.

The active reflection coefficients for the elements P2 and $\mathrm{P} 4$ in the central subarray in S-band are presented in Figs. 10 and 11. Since the obtained results don't fulfill our requirements the basic unit cell will be subject to thorough analysis of adversely affects influencing active S-parameters.
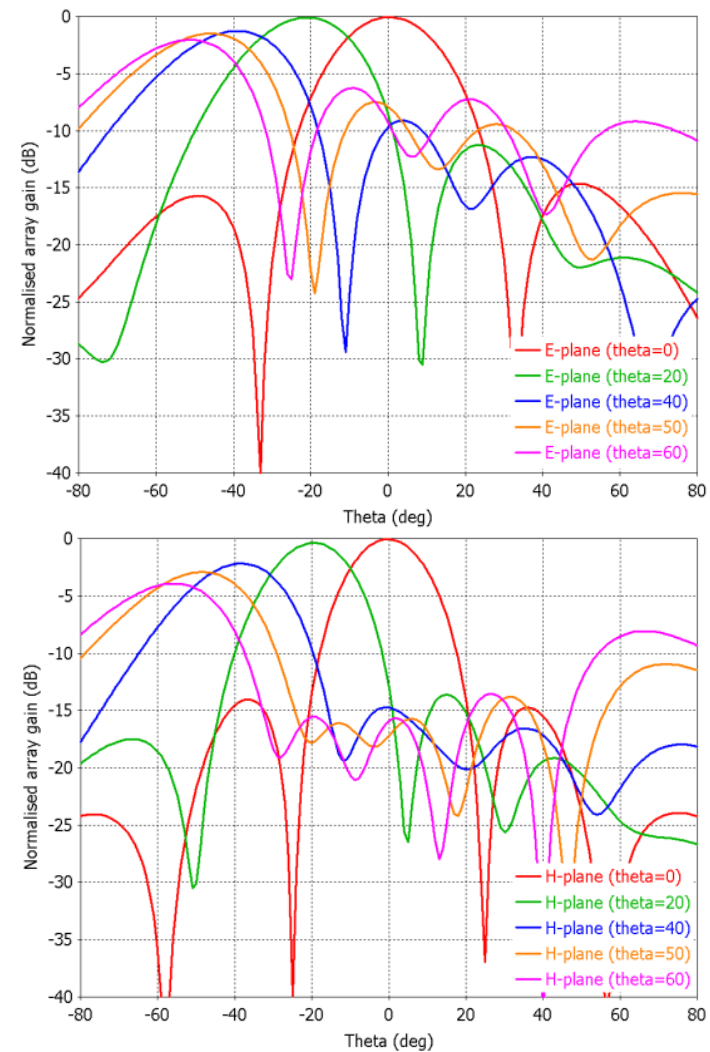

Fig. 13. Scanning performance of the array at the lower frequency band of operation at $1.4 \mathrm{GHz}$.

The scan radiation patterns are depicted in Fig. 13 and Fig. 14 for the L-band and S-band, respectively. The radiation patterns in H-plane for both bands confirm correctness of our design: grating-lobe-free beam scanning up to a maximum of 50 degrees is achieved at both frequency bands. The level of side lobes is below $-10 \mathrm{~dB}$ in this scanning range. The side lobe levels can be further reduced by applying an appropriate amplitude taper.

In contrast with H-plane, the scan performance in E-plane doesn't fulfil our expectations. The scan losses are lower in this plane but there is problem with side-lobe levels. So in further work we will analyze the scanning performances of larger antenna array based on the embedded radiation pattern 
of the central element to figure out if it is due to the triangular lattice or something else.
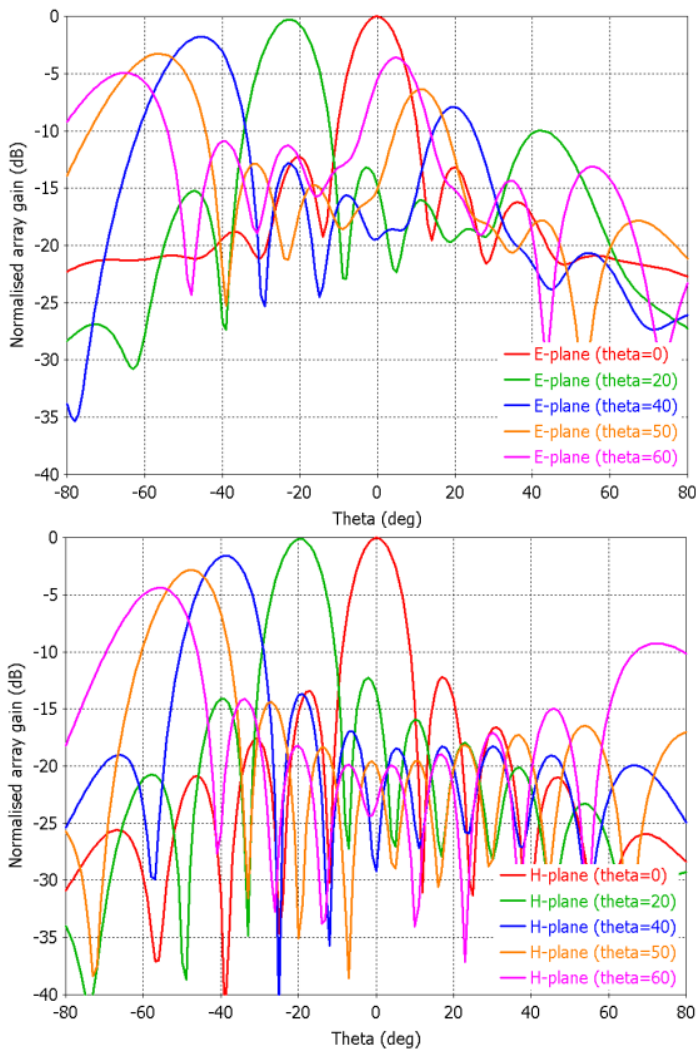

Fig. 14. Scanning performance of the array at the higher frequency band at the frequency of 2.9 GHz: E-palne (above) and H-plane (below).

\section{CONLUSIONS}

A novel concept of two-port dual-band microstrip squarering antenna for wide-angle scanning planar phased array is proposed. The evaluation of the element performances is carried out at L-band and S-band which are bands of interest for several practical radar applications. The antenna element exhibits well-defined dual-band characteristics and good subband bandwidths. Consistent and broad radiation patterns are achieved in both the operational bands with low levels of cross polarization for stand-alone element. The array element has optimal electrical dimensions to support wide-angle scanning in both bands and thus has a good potential for application in dual-band wide scanning phased arrays.

Scan performance in E-plane at the higher operational band has however demonstrated high side lobes.
Furthermore, there is open question how to correctly calculate in CST the active S-parameters of the unit cell in an infinite antenna array configuration, which consist more than one port.

The future work in this research aims at: 1) improvement of the single element performances qua active reflection coefficient in the higher frequency band, 2) verification of the multi-port unit cell's active S-parameters in infinite and finite arrays in CST-MWS ${ }^{\mathrm{TM}}$ and 3) verification of the antenna's scanning performance in triangular lattice in case of a large finite array.

\section{REFERENCES}

[1] L. B. S. Kavitha and I. J. Raglend, "A wide-scan phased array antenna for a small active electronically scanned array: a review," in Proc. Int. Conf. Circuits Power Comput. Technol., 2013, pp. 1008-1016.

[2] N. Riley, D. Riley, and J.-M. Jin, "Design and modeling of finite and low-profile, ultra-wideband phased-array antennas," in Proc. IEEE Int. Symp. Phased Array Syst. Technol., Oct. 12-15, 2010, pp. 484-491.

[3] C. T. Rodenbeck, K. Sang-Gyu, W.-H. Tu, M. R. Coutant, S. Hong, L. Mingyi, and K. Chang, "Ultra-wideband low-cost phased-array radars," IEEE Trans. Microw. Theory Techn., vol. 53, no. 12, pp. 3697-3703, Dec. 2005.

[4] D. Cavallo, A. Neto, and G. Gerini, "A 10.5-14.5 GHz wide-scanning connected array of dipoles with common-mode rejection loops to ensure polarization purity," in Proc. IEEE Int. Symp. Antennas and Propag. Soc., Jul. 11-17, 2010, pp. 1-4.

[5] Dogan, D., "A wide band, dual polarized patch antenna for wide angle scanning phased arrays," in Phased Array Systems \& Technology, 2013 IEEE International Symposium on , vol., no., pp.135-138, 15-18 Oct. 2013

[6] Haider, N.; Tran, D.P.; Roederer, A.G.; Yarovoy, A.G., "Reconfigurable L/S band phased array," in Electronics Letters , vol.47, no.23, pp.12651266, November 102011

[7] S. Maci, G.B. Gentili, "Dual-frequency patch antennas," IEEE Antennasand Propagation Magazine, vol.39, no.6, pp.13-20, Dec 1997.

[8] K. F. Lee, K. M. Luk, K. M. Mak, S. L. S. Yang, "On the use of u-slots in the designs of dual and triple-band patch antennas," IEEE Antennas and Propagations Magazine, vol.53, no.3, pp.60-74, June 2011.

[9] Valavan, S.E.; Tran, D.; Yarovoy, A.G.; Roederer, A.G., "Planar DualBand Wide-Scan Phased Array in X-Band," in Antennas and Propagation, IEEE Transactions on, vol.62, no.10, pp.5370-5375, Oct. 